World Lumen Congress 2021 | May 26-30, 2021 |

lasi, Romania

\title{
Metacognitive Regulation and Attention to Body Signals - Strategies to Prevent Academic Exhaustion
}

Camelia-Nadia BRAN \& Editha-Margareta COŞARBĂ https://doi.org/10.18662/wlc2021/09

How to cite: Bran, C.-N., \& Coşarbă, E.-M. (2021). Metacognitive Regulation and Attention to Body Signals - Strategies to Prevent Academic Exhaustion. In A. Sandu (vol. ed.), Lumen Proceedings: Vol. 17 World Lumen Congress 2021 (pp. 70-78). Iasi, Romania: LUMEN Publishing House. https://doi.org/10.18662/wlc2021/09 


\title{
Metacognitive Regulation and Attention to Body Signals - Strategies to Prevent Academic Exhaustion
}

\author{
Camelia-Nadia BRAN ${ }^{1}$, Editha-Margareta COŞARBĂ ${ }^{2}$
}

\begin{abstract}
In contemporary society, higher education students are confronted more and more with an avalanche of paradigms, models, theories, wider or narrower subject specializations, online learning, face-toface activities, blended learning, knowledge assessment, competencies assessments, etc. A possible solution for preventing the negative effects of this academic burden is to develop students' metacognitive competencies. We have developed a study on 133 participants, students in initial or continuous teacher training programs, whose aim was to the level of interrelations between academic exhaustion and the constant usage of regulation strategies and care for the body. A three-section questionnaire was applied using Google form. To test the bypothesis, we have conducted multiple comparisons between and within groups. The descriptive statistics show that the students enrolled in teacher training programs at "Aurel Vlaicu” the University of Arad declared themselves as constantly practicing reflection, planning, monitoring, and evaluation strategies when solving their academic tasks.
\end{abstract}

Keywords: Metacognitive regulation, academic exhaustion, lifestyle, attention to body signals, burnout.

\section{Introduction. Theoretical premises}

In contemporary society, higher education students are confronted more and more with an avalanche of paradigms, models, theories, wider or narrower subject specializations, online learning, face-to-face activities, blended learning, knowledge assessment, competencies assessments, readiness for workplace and a lot of other academic requirements and demands.

\footnotetext{
1 Associate professor, PhD., "Aurel Vlaicu” University of Arad, Romania, camelia.bran@uav.ro

2 Assistant professor, PhD. candidate, "Aurel Vlaicu" University of Arad, Romania, editha.cosarba@uav.ro
} 
To stimulate the student's activity and creativity, the teacher himself must be a creative and active person, to show a positive behavior and attitude in this respect. Interactive and creative instruction resizes the roles and hypostases of the teacher (Coşarbă \& Torkos, 2020). As an effect, we can see students that promote surface learning, an increased level of academic drop out and failure, graduates that lack knowledge and competencies at the end of the study period, demotivated and, sometimes exhausted students.

A possible solution for preventing such negative effects is to develop student's metacognitive competencies. Metacognitive processes allow the realization of awareness of one's learning process, the choice of optimal strategies for a certain learning sequence from the repertoire of strategies held by the student, as well as the self-regulation of learning through planning, organizing, monitoring, and regulating one's learning.

Although the development of metacognitive competencies must be one of the objectives of education, in any level of schooling, in higher education, teachers are meant to create the framework for refining students' metacognitive competencies, developing transversal competencies that transcend study disciplines and allow transfer to other areas (Bran, 2012).

Metacognitive regulation increases performance through a better allocation of attentional resources, better use of existing strategies, and better awareness of one's understanding. A consistent amount of research demonstrates a real improvement in learning when using regulatory skills and understanding how to use them in the learning process (Bran \& Balaş, 2011; Erlin et al., 2020).

When approaching the topic of metacognitive regulation, we consider three dimensions of this specific process:

a) Metacognitive planning involves the selection of appropriate strategies for accomplishing the learning task and allocating adequate resources. For example, research shows that high-performing students achieve global planning, as opposed to isolated local planning when they want to write a text (Berieter \& Scardamalia, 1987 cit. in Schraw, 1998).

b) Metacognitive monitoring refers to the learner's permanent awareness of the understanding and performance obtained in the task. Monitoring includes self-testing skills needed to control learning. Students monitor both the details (for example, the characteristics of a single item in a test) and the whole (all items in a test are monitored) (Schraw et al., 2006). It can be stated that monitoring means tracking, informing about the object level, and control involves adjusting, modifying it (Radu, 2000).

c) Metacognitive evaluation involves re-evaluating goals, revising predictions, and consolidating the information obtained. (Schraw et al., 
2006) Metacognitive knowledge, regulatory planning and monitoring capabilities are related to evaluation. Regarding the revision of a text, Bereiter \& Scardamalia (1987, cit. in Schraw, 1998) show that nonperforming "writers" are less able than those who perform to adopt the "reader perspective" and have greater difficulty in identifying and correcting problems in the text.

In the absence of metacognitive regulation strategies, students are more likely to develop academic exhaustion, lack of purpose, and decreased motivation for learning and academic achieving (Kusurkar et al., 2013; Madigan \& Curran, 2020): these are the symptoms of burnout. Maslach \& Leiter (2016) define burnout as a syndrome of emotional exhaustion, depersonalization, and reduction of professional achievement appeared in individuals involved professionally alongside others.

If in the previous years, burnout was considered to be specific to the relational professions of assistance and help, this time it appears to be found in any type of activity. At the same time, academic exhaustion is likely to predict work exhaustion and burnout (Robins et al., 2018). The well-being of students has different physical, mental, and emotional facets, in complex interaction (Dejoy \& Wilson, 2003, cit in. Grawitch et al., 2006).

Scientific literature enhances the role of educational climate in promoting organizational well-being. We mention the relational climate generated between the students, between the teachers and students or between the school management and the teachers having multiple effects at behavioral, cognitive, affective, attitudinal, and motivational levels ( Rad et al., 2019). A healthy lifestyle and attention to body signals are creating the context for decreased academic exhaustion. We have developed a study on the pre-service and in-service teacher students to test our assumptions.

\section{Objectives and hypothesis of the study}

We aimed to establish the level of interrelations between academic exhaustion in the case of prospective or in-service teachers and their constant usage of regulation strategies and care for the body.

\section{Hypothesis:}

1. The levels of subjects' metacognitive regulation strategies, attention accorded to body signal and academic exhaustion vary according to the academic program level they are enrolled at.

2. Subjects working for more years in education have developed better metacognitive regulations strategies 
3. The higher the classes they prepare to teach in, the higher the level of academic exhaustion during the attendance of teacher training program.

\section{Research design}

\subsection{Participants}

Many subject students in educational sciences at „Aurel Vlaicu” the University of Arad, were asked to complete an online google form questionnaire (133 in number). We have used a number of the stratification criteria: Academic program | he subjects are enrolled in; The academic level the subjects will teach in after graduation; Gender; Years of experience in teaching; Area they are teaching in or they would like to teach;

Crayoning a general profile of the subjects, they are mainly women, enrolled at Master programing educational sciences, having no experience in teaching or having a great experience (more than $\mathbf{1 0}$ years), teaching in primary or preschools intherrural area.

\subsection{Instruments}

The questionnaire was composed of three sections:

Section one: Metacognitive regulation, including items on a 5 steps Likert scale: 1- I never think about this issue, 2- I never think about this issue, 3- I reflect on this issue neither rarely nor often, 4- I think about this issue very often, 5 - I always think about this issue.

Section two: Academic exhaustion, adaptation of Maslach Burnout Inventory-Student Survey (MBI-SS), (Maslach et al., 2017), comprised a number of 17 items on a scale from 1 to 6,1 meaning the subjects' total disagreement with the enounce and 6 total agreements. The lower the score, the bigger the subjects' disagreements with the exhaustion affirmations, thus the less exhausted they feel. The higher the score, the more exhausted they are. $\mathrm{N}=133$, Mean $=28,42, \mathrm{SD}=11.19$.

Section three: Attention and evaluation of body signals (adaptation from Fengler, 2016) 11 items on a 7 steps scale, around dichotomic affirmations. Subjects were asked to place their answers more closed to the left $(1,2,3$, meaning Stressors of the body) or closer to the right $(5,6,7$, meaning Care given to the body). The higher the scores, the healthier the lifestyle of the subjects. $\mathrm{N}=133$, Mean $=49.71, \mathrm{SD}=2.84$ 


\subsection{Research methodology}

To test the hypothesis, we have conducted multiple comparisons between groups- means comparisons and Kruskal Wallis Test analysis. Correlation analysis (Pearson) and non-parametric tests (Spearman) were also applied between the questionnaire dimensions (planning, monitoring, evaluation, academic exhaustion, and attention to body signals).

\section{Results}

General descriptive results on the five dimensions of the questionnaire revealed high scores obtained by the subjects: metacognitive regulation behaviors (planning, monitoring, evaluation) and for the attention paid to body signals and high disagreement with the affirmations related to academic exhaustion (the low scores for academic exhaustion dimension indicate the fact that the subjects do not perceive the academic tasks as exhausting). The general descriptive results are presenting as follows:

Table 1. descriptive statistics for the questionnaire's dimensions

\begin{tabular}{|l|l|l|l|l|l|}
\hline & Planning & Monitoring & Evaluation & $\begin{array}{l}\text { Academic } \\
\text { exhaustion }\end{array}$ & $\begin{array}{l}\text { Attention } \\
\text { to Body }\end{array}$ \\
\hline $\begin{array}{l}\text { N Valid } \\
\text { Maximum } \\
\text { score }\end{array}$ & 133 & 133 & 133 & 133 & 133 \\
\hline Mean & $\mathbf{4 1 . 6 8 4 2}$ & $\mathbf{1 5}$ & $\mathbf{2 5}$ & $\mathbf{6 9}$ & $\mathbf{7 6}$ \\
\hline $\begin{array}{l}\text { Std. Error } \\
\text { of Mean }\end{array}$ & $\mathbf{7 1 0 9 1}$ & $\mathbf{1 1 . 1 9 5 5}$ & $\mathbf{2 0 . 1 1 2 8}$ & $\mathbf{2 8 . 4 2 1 1}$ & $\mathbf{4 9 . 7 0 6 8}$ \\
\hline Median & 34.0000 & .23052 & .36721 & .97006 & 1.11304 \\
\hline $\begin{array}{l}\text { Mode } \\
\text { Std. } \\
\text { Deviation }\end{array}$ & $32.00^{\mathrm{a}}$ & 12.0000 & 21.0000 & 26.0000 & 51.0000 \\
\hline
\end{tabular}

Taking into account the descriptive and inferential results between groups, we have obtained significant differences according to the "academic program" criterium, using independent samples Kruskal-Wallis test, for planning behaviors of the subjects (significance level .039) and academic exhaustions (significance level .002).

Taking into account the differences among groups on "the academic level the subjects will teach in after graduation" criteria, we 
have obtained significant differences between students only for the academic exhaustion dimension $(\mathrm{Z}=-2.211$, for $\mathrm{p}<.05)$.

Taking into account the cluster of "subjects around their number of years of experience as school teachers", we have obtained significant differences between experienced and un-experienced teachers on the planning and monitoring dimensions.

The variance analysis revealed by Kruskal Wallis Test shows that the difference between the scores for planning and monitoring are significant (for planning $\chi^{2}(4)=11.964, \mathrm{p}<.0 .02$, for monitoring $\chi^{2}(4)=10.565$, $\mathrm{p}<.04)$. As regarding the scores obtained for each subscale of the questionnaire we have obtained significant Pearson correlations for Planning \& Monitoring $(\mathrm{r}=0.670, \mathrm{p}=.000)$ (rho $=0.645, \mathrm{p}=.000$ ), Planning \& Evaluation $(\mathrm{r}=0.688, \mathrm{p}=.000)$ ( $\mathrm{rho}=0.643, \mathrm{p}=.000)$, Evaluation \& Monitoring $(\mathrm{r}=0.687, \mathrm{p}=.000)(\mathrm{rho}=0.659, \mathrm{p}=.000)$, Body \& Exhaustion $(\mathrm{r}=-0.189, \mathrm{p}=.03)(\mathrm{rho}=-0.151, \mathrm{p}=.083 \mathrm{NS})$.

\section{Discussions}

The descriptive statistics show high levels of metacognitive competencies (planning, monitoring, and evaluation) for all subjects and clusters. The students enrolled in teacher training programs at „Aurel Vlaicu" the University of Arad declared themselves as constantly practicing reflection, planning, monitoring, and evaluation strategies when solving their academic tasks. The vast majority of the respondents (cumulative percent $80 \%$ ) have expressed disagreement with the affirmations related to academic exhaustion. At the same time, $84 \%$ of respondents have expressed their attention to body signals and lifestyle obtaining scores in the upper half of the mention dimension.

Students enrolled in the master program have significantly higher competence of planning and monitoring their learning comparing with Bachelor level students. These skills are facilitated by the natural developmental phase they are in, or are due to master students' experience as teachers. $89 \%$ of Masters's students are already working as teachers in primary education or kindergartens, having thus the exercise of planning and monitoring their students' academic tasks.

The significant difference between the level of academic exhaustion of the students preparing to become teachers in primary schools and those preparing to become teachers in secondary schools could be explained by the fact that the second category of students regards pedagogical training as an adjacent curriculum to their academic education. The initial teacher 
training in Romania is organized around subject matter specialization (philology, mathematics, informatics, psychology, theology, etc) pedagogical training being an elective option for each student, coming along with more study disciplines and implicitly more academic tasks and implicit more academic exhaustion.

The results show that students who are also at the beginning of their teaching career (having between 1 and 3 or 4 to 6 years of experiences as teachers) manifest higher planning and monitoring behaviors comparing with students that are more experienced as teachers (having 7 to 10 years of experience as teachers). The younger teachers that are at the same time students in the master program, need to develop effective metacognitive regulation skills (planning, monitoring, evaluation) to cope with the multitude of professional and academic tasks that they need to solve.

Could we conclude that the lower scores for academic exhaustion are a result of good metacognitive competencies and a balanced lifestyle? The correlational study using Pearson method 2- tailed, revealed an inverted correlational level with no statistical significance.

The significant correlations $(\mathrm{p}<.01)$ were identified between the three dimensions of metacognitive regulation (planning, monitoring, evaluation) and between academic exhaustion and attention to body signals (academic exhaustion and attention to body signal $r(133)=-189, \mathrm{p}<.05)$. The higher the level of academic exhaustion, the less attention the respondents pay to their lifestyle and their body signals.

\section{Conclusions}

According to the results and analysis we can conclude that:

Hypothesis no.1 is partially confirmed only for the dimensions planning and academic exhaustion. The students enrolled in educational master programs have demonstrated a higher level of regulation when approaching the academic assignments. The students following the bachelor programing educational sciences, and those preparing to become teachers for secondary declared a higher level of academic exhaustion, comparing with the respondents enrolled in the other programs.

Hypothesis no.2. is not confirmed, the highest level of regulation strategies being obtained by the teachers in the first 6 years of their teaching career.

Hypothesis no.3 is confirmed, the students enrolled in the psychopedagogical teacher training program, manifest a higher level of academic 
exhaustion, because they combine subject matter specialization with pedagogical training.

To promote well-being among the prospective teacher students, special attention needs to be accorded to the training of metacognitive regulation strategies, starting with early childhood education to the higher education level. Higher abilities for planning and evaluation when solving the academic assignments prevent academic exhaustion manifested in lack of purpose, demotivation for learning and achieving, depression, a decrease of social interactions. A healthy lifestyle and attention paid to body signals are in close, inverted correlation with the level of academic exhaustion, thus universities must provide opportunities for relaxation, socializing, healthy food, physical exercises, and a balanced schedule.

Rethinking initial teacher training programs in Romania in a crosscurricular manner is needed to train teachers better trained from the pedagogical point of view and more adapted to the international approaches.

\section{Limits of the study}

The study is representative only for educational sciences students from "Aurel Vlaicu" the University of Arad, Romania. Although they have similar profiles with students in teacher training programs from all of Romania, we cannot generalize the findings.

Having in mind that the survey was conducted by teachers during the exam period, we can suspect a high amount of social desirability manifested in the students' answers to the questionnaire. The general analysis offered an idyllic, less probably true image of their metacognitive strategies and lifestyles. We must pay attention to the more profound, correlational, and non-parametric test results described above.

\section{References}

Bran, C. (2012). Repere pentru o invăţare eficientă [Landmarks for effective learning]. "Aurel Vlaicu" University Publishing House.

Bran, C. N., \& Balaş, E. (2011). Metacognitive Regulation And In Depth Learning. A Study On The Students Preparing To Become Teachers. Procedia Social and Behavioral Sciences Journal - Teachers for the Knowledge Society, 11, 107-111. https://doi.org/10.1016/i.sbspro.2011.01.043

Coşarbă, E. M., \& Torkos, H. (2020). The proffessional values of primary school teachers. Agora Psycho-Pragmatica, 14(1). https://www.uav.ro/jour/index.php/app/article/view/1491/1585 
Erlin, E., Rahmat, A., \& Rejeki, S. (2020). Use of metacognitive regulation strategies to increase student academic achievement in microbiology course. Journal of Physics: Conference Series, 1521, 042016. http://doi.org/10.1088/1742$\underline{6596 / 1521 / 4 / 042016}$

Fengler, J. (2016). Burnout. Strategii pentru prevenirea epuizării profesionale. Editura Trei.

Grawitch, M. J., Gottschalk, M., \& Munz, D. C. (2006). The path to a healthy workplace: A critical review of linking healthy workplace practices, employwell-being, and organizational improvements. Consulting Psychology Journal: Practice and Research, 58(3), 129-147. https://doi.org/10.1037/1065$\underline{9293.58 .3 .129}$

Kusurkar, R. A., Croiset, G., Galindo-Garre, F. \& Ten Cate, O. (2013). Motivational profiles of medical students: Association with study effort, academic performance and exhaustion. BMC Medical Education, 13, 87. https://doi.org/10.1186/1472-6920-13-87

Madigan, D. J., \& Curran, T. (2020). Does Burnout Affect Academic Achievement? A Meta-Analysis of over 100,000 Students. Educational Psychology Review, 33, 387-405. https://doi.org/10.1007/s10648-020-09533-1

Maslach, C., \& Leiter, M. P. (2016). Understanding the burnout experience: recent research and its implications for psychiatry. World Psychiatry, 15(2), 103-111. https://onlinelibrary.wiley.com/doi/full/10.1002/wps.20311

Maslach, C., Jackson, S. E., \& Leiter, M. P. (2017). Maslach Burnout Inventory Manual (4th Ed.). Menlo Park, CA: Mind Garden.

Rad, D., Roman, A., Dughi, T., Demeter, E., \& Rad, G. (2019). The dynamics of the relationship between just-for-fun online harassment and perceived school safety. International Conference on Innovation, Documentation and Education INNODOCT, 381-388. http://dx.doi.org/10.4995/INN2019.2019.10233

Radu, I. (2000). Evaluarea in procesul didactic [Evaluation in the teaching process]. Editura Didactică şi Pedagogică.

Robins, T. G., Roberts, R. M., \& Sarris, A. (2018). The role of student burnout in predicting future burnout: exploring the transition from university to the workplace. Higher Education Research \& Development, 37(1), 115-130 .https://doi.org/10.1080/07294360.2017.1344827

Schraw, G. (1998). Promoting General Metacognitive Awareness. Instructional Science, 26, 113-125. https://doi.org/10.1023/A:1003044231033

Schraw, G., Crippen, K. J., \& Hartley, K. (2006). Promoting Self-Regulation in Science Education: Metacognition as Part of a Broader Perspective on Learning. Research in Science Education, 36, 111-139. https://doi.org/10.1007/s11165-005-3917-8 